\title{
Erratum
}

\section{Diacylglycerol Acyltransferase-Inhibitory Compounds from Erythrina senegalensis}

\author{
Won Keun $\mathrm{Oh}^{1}$, Chul- Ho Lee, Jee Hee Seo, Mi Yeon Chung, Long Cui, Z. Tanee Fomum², Jong Seong Kang ${ }^{3}$, \\ and Hyun Sun Lee
}

Natural Medicine Research Center, Korea Research Institute of Bioscience and Biotechnology (KRIBB), Daejeon 305-333, Korea, ${ }^{1}$ College of Pharmacy, Chosun University, Gwangju 501-759, Korea, ${ }^{2}$ Department of Organic Chemistry, Faculty of Science, University of Yaounde I, P. O. Box 812, Yaounde, Cameroon, and ${ }^{3}$ College of Pharmacy, Chungnam University, Daejeon 305-763, Korea

The publisher regrets that in the above article, there are some faults in some words. The faults and their correction are reproduced as follows.

Legend of Fig.1

'roots' must be replaced by 'stem bark'

Page 46 18th line

'C-5' must be replaced by 'C-6'. 